\title{
A REVIEW ON RENEWABLE ENERGY INTEGRATION FOR ELECTRIC VEHICLES
}

\author{
Shubham Parmar \\ Department of Electrical Engineering \\ CHARUSAT, Anand, Gujarat, India
}

\begin{abstract}
Electric vehicles (EVs) or renewable energy (RE) sources provide the potential to significantly reduce emissions of carbon as of the economy's transport \& power generation sectors. There can be a range of impacts and benefits to the mass adoption of EVs, with the ability to aid in integrating renewable energy into current electricity grids. Present literature on EVs, power grid as well as the integration of RE is reviewed in this paper. Literature's main methods and assumptions are deliberated. Economic, environmental \& the grid effects of EVs are studied. Several research studies have been conducted on the ability of EVs to integrate Res. literature indicates that excess RE generated on a power grid can be reduced significantly. In the Vehicle to grid (V2G) idea the Plug-in electric vehicle (PEVs) can be performed as the load or as the distribution energy source. By using the V2G idea the performance of the electricity grid will increases. The efficiency, stability \& reliability will increase.
\end{abstract}

Keywords - EV, solar energy, RE, Smart grid, PV fluctuations, Low-voltage grid, Voltage fluctuation, vehicle to grid

\section{INTRODUCTION}

The transport and energy sectors in the world are straight connected to several of this century's key dynamic problem: oil peak, climate change \& energy independence. Transportation and electricity generation help compensate over 60 percent of global primary energy demand; electricity generation is a major demand for coal globally \& the majority of global oil demand is transported [1]. Different vehicle technologies, like EVs, are being residential to decrease the world's oil reliance \& reduce connected $\mathrm{CO} 2$ emissions from transport. Redevelopment and relocation of electricity based on fossil fuel were also residential \& deployed, reducing emissions of greenhouse gases \& other pollutants like Nitrous Oxides (NOx) \& sulfur dioxide (SO2). Renewable energy sources have been developed and implemented. The integration of electricity and transport, combined with electricity and RE, will decrease the world's reliance on fossil fuels $(\mathrm{FF}) \&$, consequently, the emission of greenhouse gases significantly. No. of obstacles prevents renewable energy from being integrated into the power system at a large scale [2]. RE sources like PV energy or solar power tend to differ in

\author{
Mihir Patel \\ Department of Electrical Engineering \\ CHARUSAT, Anand, Gujarat, India
}

availability without any connection to demand changes. Although natural gas turbines can be accelerated to monitor demand variations, renewable sources such as wind \& solar only come when wind winds or the sun is shining. A variety of techniques for managing supply fluctuations in various timeframes has been developed, like storage, delivery loads (or response to demand), and alternative capacity-generating [3]. These strategies can be supported by electric cars with an electric grid link. Therefore the broad introduction of electrical systems can be a critical element in integrating renewable energy into established energy systems [4].

\section{ELECTRIC VEHICLES}

\section{A. Vehicles \& energy sources -}

An EV will be definite as all vehicles that provide electricity from a battery. Gasoline or diesel fuel is used in the traditional internal combustion engine vehicle (ICEV) to generate mechanical energy for move forward. As discussed in Jorgensen [5], a variety of EV-technologies are presently in usage or below growth. A hybrid EV (HEV) has a tiny electric battery that supplies electricity to the transmission mechanism to maximize the combustion engine's operating performance. HEV battery may be electric by an engine, or by regenerative braking operation, through kinetic braking energy captured. HEVs are fuel-efficient, and this vehicle is primarily driven by liquid fuels. The idea of an HEV plug-in hybrid EV (PHEV), but with a greater battery or grid link, is similar. The grid connection helps the power of the batteries to be charged \& greater battery size allows a large distance in all-electric modes.

The electricity from the grid will be stored in a large battery and this stored electricity will be used to power the electric vehicle (BEV). Traditional fuel performance for ICEVs is $15-18 \%$, while the performance of BEVs is $60-70 \%$ [5]. EVs usage much more resources than ICEVs. Fuel cell vehicles (FCVs), which generate power in fuel cell stack from an electric process, are another type of electronic vehicle. FCVs may either be entirely dependent on the pump or built with hybrid batteries such as HEV or PHEV with a fuel supply onboard like diesel or hydrogen. Future hydrogen economic visions include transporting FCVs, if hydrogen is provided by electrical electrolysis of water by RE or biomass sources, then 


\section{International Journal of Engineering Applied Sciences and Technology, 2020 \\ Vol. 5, Issue 8, ISSN No. 2455-2143, Pages 247-254 \\ Published Online December 2020 in IJEAST (http://www.ijeast.com)}

the renewable sources are used for FCVs. The huge common of hydrogen in the world is made from fossil fuels and there are still a few barriers to creating a sustainable hydrogen economy [3]. And although hydrogen as of electrolysis represents a significant future use of renewable energy, the transition into hydrogen economy is a too large issue to discuss in this paper. HEVs can also be provided from RE sources if traditional transportation fuels such as ethanol and biodiesel can be covered by sustainable biofuels. PHEVs can utilize biofuels in their internal combustion engines through renewable energy from the grid may be used entirely by both PHEVs and BEVs. Those that can store energy from the grid are vehicle technologies that are measured for this work: PHEVs or BEVs (from this paper known as EVs).

\section{B. Charging \& grid connections -}

EVs battery can be charged by the various charging plans from the power grid. A basic or unconstrained charge plan is a device in which that vehicle starts to charge until it is connected to the grid immediately.

The battery charging is offset by a staggering charging schedule by three hours, for example. Nighttime charging plans to pause the charging in the course of the night where the price of power is smaller and morning batteries are fully charged. The intelligent charging of vehicle is regulated intelligently by utility or device operator. It may be direct charging or indirect charging. Dallinger \& Wietschel [6] says that indirect charging is better compared to direct charging.

In smart charging, the vehicle starts charging when it is most beneficial. And this could be once the electricity price is low, demand is low \& after there is excess capacity. The rate can differ under such parameters set by the driver; the key restriction is the full charge of the vehicle by morning. [7].

An EV that is up to store power or reoccurrence it to the electric grid is a V2G capable EV. Power V2G is an interesting concept that Kempton or Letendre first proposed [8]. The writers proposed that $\mathrm{V} 2 \mathrm{G}$ can be used to make a profit for owners if electricity is applied to deliver useful services to the grid under such circumstances. A V2G-capable electricity system will store the energy renewable from the low demand and return to the grid as needed.

\section{SOLAR ENERGY (SE)}

$\mathrm{SE}[9]$ is Sunlight production. This is a renewable or ecofriendly alternative source of energy. Enough solar energy reaches the earth each hour for a whole year to satisfy the global energy demand. We needed electricity every hour in today's generation. It is easy to drawn energy from the sunlight. So solar energy is very efficient \& environment friendly.
As per the principle of the photoelectric effect, PV technology directly transforms incident solar energy into electricity. PV is appropriate for low and high direct irradiance areas. PV technology. Solar panels made of various kinds of photovoltaic materials are used for the generation of electricity using PV technology. Materials that are most widely used include mono- or poly-crystalline silicon, cadmium telluride (CdTe), gallium arsenide (GaAs), and triple solar cells made of Indium gallium (InGaP). In general, solar cell [10] is a small source of electricity. Solar cells form a multiplex cell module, which is then combined in a PV array, consisting up to some meters in length to produce electrical power on a larger scale. Hundreds of solar arrays are attached to procedure comprehensive structure for power generation, according to NREL [11].

Solar generation can be either directly by using PV cells [10] or circuitously in capturing \& concentrating solar power (CSP) [12] into condensation generated and then added to electricity turbines. The PV outcome refers to the theory that light photons drive electrons into a higher energy state. Direct power generation from solar radiation. While PVs are first used in power generation applications, there are many PV generating systems for daily use, such as isolated homes, vessels, water pumps, e-cars, emergency telephones \& remote sensing on the roadside.

Concentrating solar thermal systems (CST) use suntracking systems and optic devices to focus on a wide region of sunlight in a lesser region. CSE is then applied to a conventional energy plant as a heat source. There is a variety of technology for concentrating. A) Parable troughs, b) solar dishes, c) linear Fresnel's, \& d) solar towers are core concentrative terms. High temperatures \& hence high temperatures efficiency is the main purpose of solar intensity.

PV cells convert sunlight to direct power. In general, a charging controller or a charging regulator is a voltage \& a current regulator to avoid overcharging of batteries. The voltage or power from the solar panels to the battery is regulated. The majority of "12-volt" panels reach 16 to 20 volts, so the overcharging damage will occur if batteries are not handled. To be fully charged, most batteries need about 14 to 14.5 volts. Battery System serves as electric power storage while electricity is not obtainable i.e. at night. The direct current from this system is converted to an inverter. 


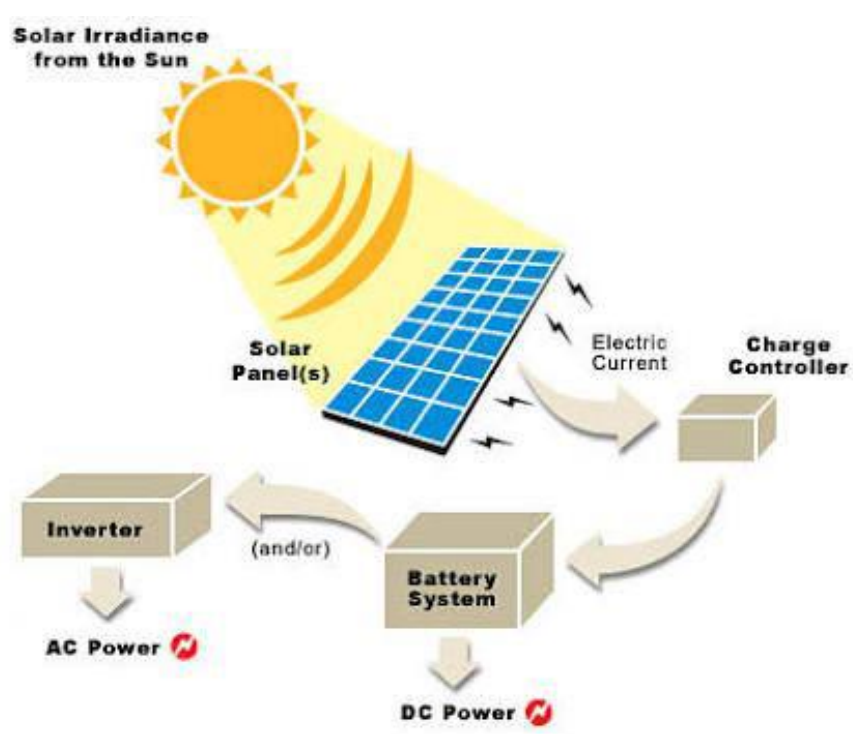

Figure 1 Working of solar energy

\section{A. GRID-CONNECTED (GC) PV POWER SYSTEM}

Electricity generating solar PV system connected to the grid is a PV system connected to the grid (fig 2). Grid PV consists of one or two solar panels, a power conditioning, and a network adapter. This includes small residential \& commercial rooftop systems or large power stations. GC system rarely requires an optimized battery solution since it is still very costly as compared to standalone energy systems. GC-PV system provides excess power to the utility grid beyond use by the connected load. [13]

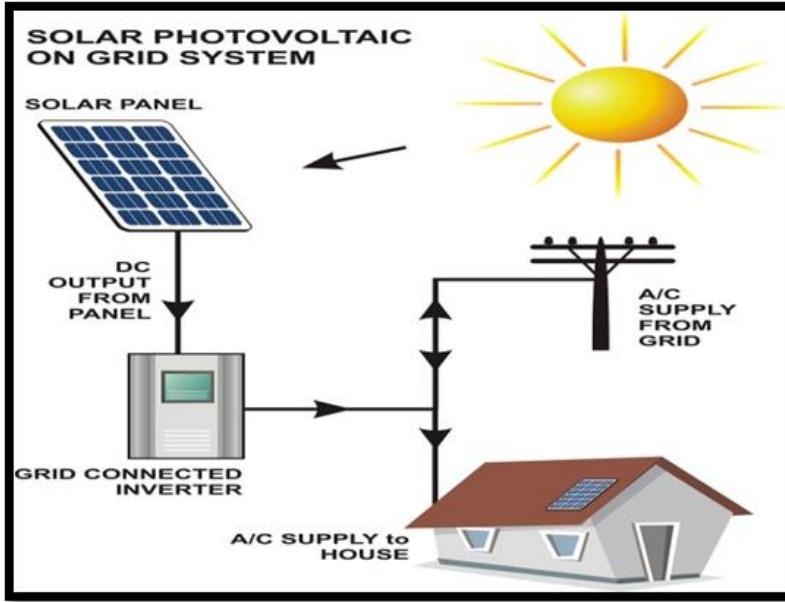

Figure 2 Solar Photovoltaic on Grid System

\section{a) Operation}

A load of most consumers can be met with residential grid-connected rooftop systems with power over 10 kilowatts. [14] The grid, where it is consumed by other consumers, would be supplied with surplus electricity. Feedback is provided by a meter to track the transmission of power. In this scenario, the user may purchase grid energy, but less than previously, for PV wattage, may be lower than normal usage. If the photovoltaic wattage exceeds normal consumption significantly, electricity produced by the panels exceeds the demand substantially. The excess power will generate revenue if it is sold to the grid in that situation. The consumer has to pay the cost of electricity used less than the amount that electricity is produced, as per the agreement with the local grid energy provider. If more power is generated than used, this would be a negative number. [15] PV device connection can only be done by a consumer-to-utility interconnection agreement [15].

When the power is proposed for distribution to a PG, electrical power from PV panels needs to be converted to alternating current using a power inverter. Inverter sits amid solar system \& grid or can be a large stand-alone unit or an AC module that can be wired to a single solar panel by small inverter. The inverter shall regulate the grid, waveform, or voltage of frequencies. The inverter must notice a lack of grid supply or just not power the grid.

\section{b) ADVANTAGES}

- Comparatively simpler to install X Grid-connected PV systems, since they don't need a system battery. [13]

- The benefit of optimal use of generated power is the interconnection of PV networks since no data losses are required.

- GC-PV system will decrease the electricity bill of the customer.

\section{c) DISADVANTAGES}

- PV connected to the grid will cause voltage control problems. The traditional grid works under one-way or radial flow hypotheses. Yet injected electricity in grid growths voltage or can take out levels of $\pm 5 \%$. [16]

- GC-PV will affect the value of electricity. The intermittent nature of PV means fast voltage changes. This not only uses voltage regulators because of regular changes but can also lead to voltage flecks. [17]

\section{B. PHOTOVOLTAIC FLUCTUATIONS}

The distribution system operators will poses unpredicted challenges in the low voltage (LV) grid due to an ongoing 


\section{International Journal of Engineering Applied Sciences and Technology, 2020 \\ Vol. 5, Issue 8, ISSN No. 2455-2143, Pages 247-254 \\ Published Online December 2020 in IJEAST (http://www.ijeast.com)}

surge in photovoltaic (PV) generation capacity. The output of the PV system will vary during daytime due to the passing clouds [18].

The distribution system operators will poses unpredicted challenges in the low voltage (LV) grid due to an ongoing surge in photovoltaic (PV) generation capacity. The output of the PV system will vary during daytime due to the passing clouds [18].

Power quality problems arise from the irregular nature of the PV output. The key issues associated with the quality of energy associated with the rapid output of PV are the voltage fluctuations \& light flickers that are induced by variations of voltage [19]. Voltage fluctuations or flickering can cause damage to grid electrical devices [20].

It's hard to predict energy generation by renewable sources; it depends on the environment. Also, when small parts are shaded by clouds, the performance of the PV module may be greatly decreased.

These transients can cause serious voltage problems in large-scale PV generation. In this case, tap-changing transformers or voltage ampere-reactive systems are not ideal for voltage regulation since the PV generation variability will take place in too small a time frame, as well as the equipment, cannot handle it. [20, 21, 22].

In the future, distribution systems operators will have to use the mechanisms to mitigate power-quality issues arising from rapid PV fluctuations to ensure future compliance with the standards of power quality.

Electric vehicles (EVs) are lately measured as an interesting technology for mitigation of the photovoltaic fluctuation.

\section{ELECTRIC VEHICLE IMPACTS AND PERFORMANCE}

\section{A. Economic impacts (EI)}

EI of EVs is categorized into 2 parts. The first part is the vehicle owner and the second part is the electricity system. Better battery technology \& mass production are expected to improve the lifecycle economy of EVs. BEV's cost is greater than PHEV's. Both are more costly than the traditional IC engine [23]. However, EVs are much less costly than IC motor vehicles as the electric motor is highly powerful.

\section{B. Environmental impacts}

The most frequently slow output applied to assess the environmental consequences of network-powered changes to EVs is $\mathrm{CO} 2$ emissions. Integrating electricity or transport sectors reduces emissions of carbon dioxide by 85\% [24]. They are discussing the intensity of emissions $(\mathrm{gCO} 2 \mathrm{e} / \mathrm{kWh})$ for energy used for charging by EV. The average grid intensity is used in most studies to represent a situation where EVs are usually followed and can be used as part of the daily demand profile. Other studies contend that marginal intensity [25] is used, where EV energy is allocated to the emissions of the marginal generation unit. In general, it can be found that even with electrical systems by high fossil fuel generation, EVs minimize overall $\mathrm{CO} 2$ emissions because the electric motor is highly powerful relative to internal combustion engines.

\section{Grid impacts}

EVs affect power, performance, or need grid power, especially when the vehicle is charged with restriction. When a basic recharge technique is applied [25], peak loads increase. It also calls for increased investment in capacity generation and transmission. When the vehicle uses an adaptive charging strategy, the vehicles raise the total load and use the base charging devices. And also it does not require any extra installed capacity [26, 27].

Other impacts of EVs on-grid include higher wear on transformers, overloading, or problems in terms of power quality [28]. The EVs and V2G are controlled to have very little effect on losses or voltage of the delivery system [29]. Even more, studies have established delivery charge level plans to preserve power quality or prevent congestion issues arising from the generally accepted use of EVs. [30, 31]. The effect of EVs at low EV penetrations are negligible on residential distribution transformer. But the effect is increased as no. of EVs increases. A high number of EVs leads to voltage limit violations, transformer overload \& increase line losses [32]. To combine more EVs in distribution networks safely, these latest management approaches are necessary.

\section{BenEFITS \& ChALLENGES OF VEHICLE-TO-GRID (V2G)}

\section{A. BENEFITS OF VEHICLE-TO-GRID}

\section{a) Ancillary Services}

In PG, supply \& demand must be maintained, supply $\&$ demand regulated, and electricity transfer from the seller to the buyer provided via Ancillary services. The two-way V2G paradigm offers better quality ancillary services than those offered at current. More PEVs must be obtained by the transistors in the community to provide a greater and needed load for utilities [33, 34].

\section{- Voltage \& Frequency Regulation}

Regulation services represent the $1^{\text {st }}$ phase for $\mathrm{V} 2 \mathrm{G}$ since the vehicle power storage device is of high market demand and has low stress $[35,36]$. To balance supply and demand, frequency regulation is used [37]. The frequency regulation is attained by cycling large generators that are expensive [38]. In its fast charging or discharging speeds, V2G is a good alternative to frequency change [39]. The voltage regulator is used for reactive power to balance supply \& demand. PEVs 


\section{International Journal of Engineering Applied Sciences and Technology, 2020 \\ Vol. 5, Issue 8, ISSN No. 2455-2143, Pages 247-254 \\ Published Online December 2020 in IJEAST (http://www.ijeast.com)}

have fast control signals that can be independently controlled for each PEV [40]. The charger will reduce inductive or reactive power by choosing the correct current phase angle [41]. If grid voltage decreases, the vehicle charging will be shut down as well as the vehicle charging will begin when the grid voltage becomes high [42]. By connecting multiple PEVs, transmission lines or voltage overloads, as well as stability issues, may occur in low voltage. [43].

The union controls the transfer of power by three steps to ensure a stable frequency in the delivery system. The primary, secondary \& tertiary frequency control $[44,45]$. By charging PEVs battery it can provide regulation down and if there is a need of the rule up then the battery will discharge in grid [35]. The control of secondary and tertiary frequency is based on the bid. The lower bid is activated first as the need for regulation increases. As the regulation is provided means a reduced cost fee and this is beneficial for PEVs [46].

\section{- $\quad$ Load Levelling (Load Shifting)}

By charging during high demand or charging during low demand, V2G can level power load. Local \& global smart charging monitoring approaches were described by K. Mets [47]. By doing the smart charging, the peak load, as well as the load curve, would be reduced. For leveling the grid, PEVs should be paid at night. The design of the battery charger is regulated to minimize the overall load and to increase energy demand $[48,49]$.

\section{b) Renewable Energy Supporting \& Balancing}

The energy generated in the intermittent wind and solar energy plants can be used to combine PEV with renewable to buffer and store energy [39, 50, 51]. For instance, the sun is only available during the day and wind power due to the unpredictable wind speeds is more complex. This will lead to imbalance [52]. Kempton or Tomic [53] examine that this fluctuation would be resolved by V2G. If renewable grid capacity is very high, central power plants must either their output to reinstate equilibrium, or distributed generation components must be decreased. PEVs may be used by discharging or charging PEVs to match consumption or generation. Extra renewable can be processed by PEVs. This extra power can be used to drive the vehicle or later power the grid [42]. The V2G would also improve grid stability to make better use of intermittent renewables.

\section{B. CHALLENGES OF V2G}

V2G has many advantages, but the increased amount of PEV will influence the efficiency of the power delivery system, by overloading transformers, cables, and transducers. This decreases productivity and can require additional starts, producing voltage and harmonic variations [54, 55]. Battery infrastructure and high initial costs relative to IC engine vehicles are the biggest challenges in V2G.

\section{a) Battery Degradation}

The degradation of the battery relies on the energy recovered or based on the depth of the discharge or duration of cycling. For auxiliary networks, bidirectional V2G will slash battery life. The battery costs are very high as the technologies continue to grow. By using a battery in the middle of a state of charge (SOC) range is a good way to slow degradation [56]. Depending on the chemical composition or development process battery life cycle varies greatly. Currently, the Li-ion batteries are the best for V2G due to its long service life and high capacity. Li-ion batteries have around 2000 to 2400 deep cycles [57].

\section{b) Effects on Distribution Equipment}

The impact of PEV charges on delivery equipment is considerable [58]. The battery charger will easily service charge the delivery facilities, depending on the PEVs penetration scenarios. This increases transformer distribution fails, fluctuation of voltage, harmonic distortion, and high demand [59]. This would increase additional investments in large underground wires, general lines, and more room for transformers [60]. Distribution transformer life will decrease and the quality of the insulation will also decrease. Large PEVs penetration with poor coordination of charging affects the power grid. By the uncontrolled indicting at 50\% PEVs penetration the life of the transformer will decrease by around 200 to $300 \%$ [61]. To decrease the effect of PEVs charging on distribution by demand response. The problem of a voltage drop may be minimized by using a condenser bank or a load tap changer [62] or by reactive PEV charger control.

\section{c) Investment Costs \& Energy Losses}

Based on the charging approach, energy losses of up to $15 \%$ of the average current network cost may increase to $40 \%$ during off-peak hours if 60 percent of total vehicles are PEVs.

\section{CONCLUSION}

The introduction of EVs, like a lower vehicle running costs, decreased $\mathrm{CO} 2$ emissions, as well as supporting and improving grid power and stability, may expect a certain range of positive impacts if appropriate technology is implemented. However, the potential of EVs to help incorporate RE sources into the power grid is perhaps important. This has the potential to reduce both energy generation or transport carbon emissions. It should be observed that while EVs can significantly reduce some adverse implications of large-scale $\mathrm{RE}$, other methods \& technologies are probably required to incorporate the high level of the RE penetration. EVs give several possible advantages to the grid, with the potential to add intermittent sources of RE. The capacity, limits, and 


\section{International Journal of Engineering Applied Sciences and Technology, 2020 \\ Vol. 5, Issue 8, ISSN No. 2455-2143, Pages 247-254 \\ Published Online December 2020 in IJEAST (http://www.ijeast.com)}

impacts that transport and the electricity industry can be combined through electricity and renewable energy must be understood. This will affect the policies and planning of infrastructure to optimize the environmental \& economic gains of all innovations while reducing global greenhouse gas emissions and reliance on fossil fuels. System providers, vehicle owners as well as the environment benefit from PEV. PEV's can serve as stored energy tools \& serve as a reservoir for the prevention of unexpected outages if they are provided with sufficient on-board power source, energy storage connections, and digital charger control hardware. It benefits the environment and accelerates the use of PEVs.

\section{REFERENCE}

[1] Key World Energy STATISTICS, (2011), Paris: International Energy Agency.

[2] G. Boyle, Renewable Electricity and the Grid: The Challenge of Variability, london: Earthscan Publications.

[3] Harvey LDD, (2010), Carbon-Free Energy Supply, London: Earthscan.

[4] Lund H, Kempton W, "Integration of renewable energy into the transport and electricity sectors through V2G".

[5] K. Jorgensen, "Technologies for electric, hybrid and hydrogen vehicles: Electricity from renewable energy sources in transport," Elsevier.

[6] Dallinger D, Wietschel M, "Grid integration of intermittent renewable energy sources using priceresponsive plug-in electric vehicles," Elsevier.

[7] Lunz B, Yan Z, Gerschler J, Sauer D, (2012), "Influence of plug-in hybrid electric vehicle charging strategies on charging and battery degradation costs," Elsevier.

[8] Kempton W, Letendre S, "ELECTRIC VEHICLES AS A NEW POWER SOURCE FOR ELECTRIC UTILITIES," Elsevier.

[9] D. S. P. Sukhatme, Book of "Solar Energy", Tata McGraw Hill Publication.

[10] Shruti Sharma, Kamlesh Kumar Jain, Ashutosh Sharma, (2015), Solar Cells: In Research and Applications-A Review, Materials Sciences and Applications.

[11] Solar photovoltaic technology, National Renewable Energy Laboratory.

[12] Md TasbirulIslam, NazmulHuda, (2018), A comprehensive review of state-of-the-art concentrating solar power (CSP) technologies: Current status and research trends," Elsevier.

[13] Elhodeiby, A.S.Metwally, H.M.B, (2011); Farahat, "PERFORMANCE ANALYSIS OF 3.6 KW ROOFTOP GRID CONNECTED PHOTOVOLTAIC SYSTEM IN EGYP," International Conference on Energy Systems and

\section{Technologies.}

[14] "Grid Connected PV Systems," (2015).

[15] "Homeowners Guide to Financing a Grid-Connected Solar Electric System," Energy Efficiency \& Renewable Energy, 2015.

[16] S. Steffel, (2015), "Challenges for Distribution Feeder Voltage Regulation with Increasing Amounts of PV," Energy Efficiency \& Renewable Energy.

[17] J. G. KASSAKIAN, (2015), "MIT Study on the Future of the Electric Grid," MIT Energy Initiative.

[18] de la Parra I, Marcos J, García M, Marroyo L, (2015), "Control strategies to use the minimum energy storage requirement for PV power ramp-rate control," Elsevier.

[19] Shivashankar S, Mekhilef S, Mokhlis H, Karimi M, (2016), "Mitigating methods of power the fluctuation of photovoltaic (PV) sources - a review," Renewable and Sustainable Energy Reviews, pp. 1170-1184.

[20] Zhao K, Ciufo P, Perera S, (2013), "Rectifier capacitor filter stress analysis when subject to Regular voltage fluctuations," IEEE Transactions on Power Electronics.

[21] Masato Oshiro, (2010), "Optimal voltage control in distribution systems with coordination of distribution installations," International Journal of Electrical Power \& Energy Systems.

[22] Foster JM, Trevino G, Kuss M, Caramanis, (2013), "Plug-In Electric Vehicle and Voltage Support for Distributed Solar: Theory and Application," IEEE Systems Journal, vol. 7, no. 4, pp. 881-888.

[23] Thomas C,(2009) "Fuel cell and battery electric vehicles compared," International Journal of Hydrogen Energy.

[24] Juul N, Meibom P,(2011) "Optimal configuration of an integrated power and transport system," Energy, vol. 36, no. 5, pp. 3523-3530.

[25] Ma H, Balthser F, Tait N, Riera-Palou X, Harrison A,(2012) "A new comparison between the life cycle greenhouse gas emissions of battery electric vehicles and internal combustion vehicles," Energy Policy, vol. 44, pp. 160-173.

[26] Kristofferson T, Caption K, Meibom P,(2011) "Optimal charging of electric drive vehicles in a market environment.," Applied Energy, vol. 88, no. 5, pp. 19401948.

[27] Denholm P, Short W, "An evaluation of utility system impacts and benefits of optimally dispatched plug-in hybrid electric vehicles," National Renewable Energy Laboratory.

[28] Green R, Wang L, Alam M,(2011) "The impact of plugin hybrid electric vehicles on distribution networks: A review and outlook," Renewable Sustainable Energy Review, vol. 15, no. 1, pp. 544-553.

[29] Ma Y, Houghton T, Cruden,(2012) "Modeling the 


\section{International Journal of Engineering Applied Sciences and Technology, 2020 \\ Vol. 5, Issue 8, ISSN No. 2455-2143, Pages 247-254 \\ Published Online December 2020 in IJEAST (http://www.ijeast.com)}

Benefits of Vehicle-to-Grid Technology to a Power System," IEEE Transactions on Power Systems, vol. 27, no. 2, pp. 1012 - 1020.

[30] Sundstrom O, Binding C,(2011) "Flexible Charging Optimization for Electric Vehicles Considering Distribution Grid Constraints," IEEE Transactions on Smart Grid, vol. 3, no. 1, pp. 26 - 37.

[31] Richardson P, Flynn D, Keane A,(2012) "Local Versus Centralized Charging Strategies for Electric Vehicles in Low Voltage Distribution Systems," IEEE Transactions on Smart Grid, vol. 3, no. 2, pp. 1020 - 1028.

[32] Papadopolous P, Skarvelis-Kazakos S, Grau I,(2012) Cipcigan L, Jenkins N, "Electric vehicles' impact on British distribution networks," IET Electrical Systems in Transportation.

[33] C. Guille and G. Gross,(2009) "A conceptual framework for the vehicle-to-grid (V2G) implementation," Energy Policy, vol. 37, no. 11, pp. 4379-4390.

[34] C. D. White and K. M. Zhang,(2011) "Using Vehicle-togrid Technology for Frequency Regulation and Peak-load Reduction," Journal of Power Sources, vol. 196, no. 8, pp. 3972-3980.

[35] J. Tomic and W. Kempton, "Using fleets of electric-drive vehicles for grid support," Journal of Power Sources, vol. 168 , no. 2 , pp. $459-468$.

[36] De Los Rios, J. Goentzel, K. E. Nordstrom, and C. W. Siegert,(2012) "Economic analysis of vehicle-to-grid (V2G)-enabled fleets participating in the regulation service market," IEEE PES Innovative Smart Grid Tech.

[37] D. Wu, K. T. Chau, C. Liu, S. Gao, and F. Li,(2012) "Transient Stability Analysis of SMES for Smart Grid with Vehicle-to-Grid Operation," IEEE Trans. Smart Grid, vol. 3, no. 1, pp. 1-4.

[38] C. Wu, H. Mohsenian-Rad, and J. Huang,(2012) "Vehicle-to-Aggregator Interaction Game," EEE Trans. Smart Grid, vol. 3, no. 1, pp. 434-442.

[39] W. Kempton and J. Tomic, "Vehicle-to-grid Power Fundamentals: Calculating Capacity and Net Revenue," Power Sources, vol. 144, no. 1, p. 268-279.

[40] W. Kempton, J. Tomic, S. Letendre, "Vehicle-to-Grid Power: Battery, Hybrid, and Fuel Cell Vehicles as Resources for Distributed Electric Power in California," CEPA.

[41] C. Wu, H. M. Rad, J. Huang, and J. Jatskevich,(2012) "PEV-Based Combined Frequency and Voltage Regulation for Smart Grid," IEEE PES Innovative Smart Grid Tech.

[42] K. Clement-Nyns, E. Haesen, and J. Driesen,(2011) "The Impact of Vehicle-to-grid on the Distribution Grid," Electric Power Systems Research, vol. 81, no. 1, pp. 185192.
[43] J. P. Lopes, F. Soares, and P. R. Almeida, "Identifying Management Procedures to Deal with Connection of Electric Vehicles in the Grid," IEEE Power Tech.

[44] M. D. Galus, M. Zima, and G. Andersson,(2010) "On Integration of PHEVs into Existing Power System Structures," Energy Policy, vol. 38, no. 11, pp. 67366745.

[45] "Union for the Coordination of Transmission of Electricity (UCTE), "Operation Handbook".

[46] S. L. Andersson, A.K. Elofsson, M.D. Galus, L. Göransson, S. Karlsson, and F. Johnsson,(2010) "Plug-in Hybrid Electric Vehicles as Regulating Power Providers: Case studies of Sweden and Germany," Energy Policy, vol. 38, no. 6, pp. 2751-2762.

[47] K. Mets, T. Verschueren, W. Haerick, C. Develder, and F. De Turck,(2010) "Optimizing Smart Energy Control Strategies for Plug-in Hybrid Electric Vehicle Charging," IEEE/IFIP Network Oper. Manage. Symp. Workshops (NOMS), pp. 293-299.

[48] F. Koyanagi and Y. Uriu, "A Strategy of Load Leveling by Charging and Discharging Time Control of Electric Vehicles," IEEE Trans. Power System, vol. 13, no. 3, p. 1179-1184.

[49] "IEEE Standard for Interconnecting Distributed Resources with Electric Power Systems," IEEE Std. 1547.

[50] J. R. Pillai and B. Bak-Jensen,(2011) "Integration of Vehicle-to-grid in the Western Danish power system," IEEE Trans. Sustainable Energy, vol. 2, no. 1, p. 12-19.

[51] T. Al-Awami and E. Sortomme, "Solar-to-vehicle (S2V) Systems for Powering Commuters of the Future," $J$. Power Sources, p. 539-542.

[52] T. Al-Awami and E. Sortomme,(2012) "Coordinating Vehicle-to-Grid Services With Energy Trading," IEEE Trans. Smart Grid, vol. 3, no. 1, pp. 453-462.

[53] W. Kempton and J. Tomic, "V2G Power Implementations: From Stabilizing the Grid to Supporting Large Scale Renewable Energy," J. Power Sources, vol. 144, no. 1, p. 268-279.

[54] E. Sortomme, M. Hindi, S. MacPherson, and S. Venkata, (2011)"Coordinated Charging of Plug-in Hybrid Electric Vehicles to Minimize Distribution System Losses," IEEE Trans. Smart Grid, vol. 2, no. 1, p. 198-205.

[55] M. Bojrup, P. Karlsson, M. Alakula, B. Simonsson, "A Dual Purpose Battery Charger for Electric Vehicles," IEEE Power Electronics Specialists Conf. (PESC), pp. 565-570.

[56] S. Han, S. Han, and K. Sezaki,(2012) "Economic Assessment on V2G Frequency Regulation Regarding the Battery Degradation," IEEE PES Innovative Smart Grid Tech. Conf. (ISGT),. 
[57] B. D. Williams and K. S. Kurani, "Commercializing Light-duty plug-in/plug-out Hydrogen FC Vehicles: Mobile Electricity Technologies and Opportunities," $J$. Power Sources, vol. 166.

[58] M. J. Ruthrford and V. Yousefzadeh,(2011) "The Impact of Electric Vehicle Battery Charging on Distribution Transformers," IEEE Applied Power Electronics Conf. (APEC), pp. 396-400.

[59] S. S. Raghavan and A. Khaligh,(2012) "Impact of Plug-in Hybrid Electric Vehicle Charging on a Distribution Network in a Smart Grid Environment," IEEE PES Innovative Smart Grid Tech. Conf. (ISGT).

[60] J. Lassila, J. Haakana, V. Tikka, and J. Partanen, (2012) "Methodology to Analyse the Economic Effects of Electric Cars as Energy Storages," IEEE Trans. Smart Grid, vol. 3, no. 1, pp. 506-516.

[61] R. Moghe, F. Kreikebaum, J. E. Hernandez, R. P. Kandula, and D. Divan,(2011) "Mitigating Distribution Transformer Lifetime Degradation Caused by GridEnabled Vehicle (GEV) Charging," IEEE Energy Conversion Cong. (ECCE), pp. 835-842.

[62] K. Clement-Nyns, E. Haesen, and J. Driesen, "The Impact of Charging PHEVs on a Residential Distribution Grid," IEEE Trans. Power System, vol. 25, no. 1, pp. 371-380. 